\title{
RESEARCH
}

Open Access

\section{Combination of SB431542, Chir9901, and Bpv as a novel supplement in the culture of umbilical cord blood hematopoietic stem cells}

\author{
Morteza Zarrabi ${ }^{1,2+}$, Elaheh Afzal $^{2+}$, Mohammad Hassan Asghari $^{3}$ and Marzieh Ebrahimi ${ }^{1 *}$ (D)
}

\begin{abstract}
Background: Small molecule compounds have been well recognized for their promising power in the generation, expansion, and maintenance of embryonic or adult stem cells. The aim of this study was to identify a novel combination of small molecules in order to optimize the ex vivo expansion of umbilical cord blood-derived CD34 ${ }^{+}$cells.

Methods: Considering the most important signaling pathways involved in the self-renewal of hematopoietic stem cells, CB-CD34 ${ }^{+}$cells were expanded with cytokines in the presence of seven small molecules including SB, PD, Chir, Bpv, Pur, $\mathrm{P} \mu$, and NAM. The eliminativism approach was used to find the best combination of selected small molecules for effective ex vivo expansion of $\mathrm{CD}_{3} 4^{+}$cell. In each step, proliferation, self-renewal, and clonogenic potential of the expanded cells as well as expression of some hematopoietic stem cell-related genes were studied. Finally, the engraftment potential of expanded cells was also examined by the mouse intra-uterine transplantation model.

Results: Our data shows that the simultaneous use of SB431542 (TGF- $\beta$ inhibitor), Chir9901 (GSK3 inhibitor), and Bpv (PTEN inhibitor) resulted in a 50-fold increase in the number of $\mathrm{CD} 34^{+} \mathrm{CD} 38^{-}$cells. This was further reflected in approximately 3 times the increase in the clonogenic potential of the small molecule cocktail-expanded cells. These cells, also, showed a 1.5-fold higher engraftment potential in the peripheral blood of the NMRI model of in utero transplantation. These results are in total conformity with the upregulation of HOXB4, GATA2, and CD34 marker gene as well as the CXCR4 homing gene.
\end{abstract}

Conclusion: Taken together, our findings introduce a novel combination of small molecules to improve the yield of existing protocols used in the expansion of hematopoietic stem cells.

Keywords: Cord blood, Hematopoietic stem cells, Small molecules, Ex vivo expansion

\footnotetext{
* Correspondence: mebrahimi@royaninstitute.org

${ }^{\dagger}$ Morteza Zarrabi and Elaheh Afzal contributed equally to this work.

'Department of Stem Cells and Developmental Biology, Cell Science

Research Center, Royan Institute for Stem Cell Biology and Technology, ACEC

R, P.O. Box, Tehran 19395-4644, Iran

Full list of author information is available at the end of the article
}

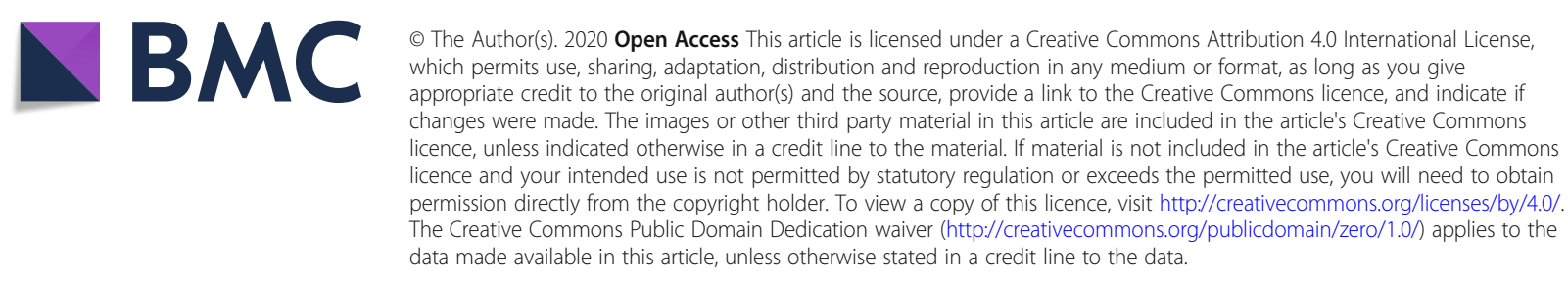




\section{Introduction}

The umbilical cord blood (UCB) as one of the most valuable and convenient sources of hematopoietic stem cells (HSCs) has a great potential for the treatment of various hematological, non-hematological disorders, and cancers [1-4]. However, the limited number of HSCs in a UCB unit has limited its use to the young patients. In this regard, ex vivo expansion is one of the main solutions proposed to acquire a sufficient number of HSCs $[5,6]$. Therefore, in recent years, many efforts have been made to identify the factors affecting the self-renewal of the umbilical cord $\mathrm{CD}_{3} 4^{+}$cells as well as the more primitive hematopoietic stem and progenitors, $\mathrm{CD} 34^{+} \mathrm{CD} 38^{-}$cells [7].

The use of small molecules in the field of hematopoietic stem cell research has grown rapidly in recent years, as they are good tools for controlling the variety of cellular processes [8]. There are different approaches to select small molecules in HSC expansion; induction of self-renewal [9], inhibition of lineage commitment differentiation [10], and inhibition of HSC apoptosis $[11,12]$. In the present study, we hypothesized that the best expansion is achieved when the proliferation, survival, and self-renewal pathways are induced, while the apoptosis and differentiation pathways are inhibited, simultaneously. Therefore, through data mining, a limited set of seven small molecules were selected which are as follows:

- SB431542 (SB) and Purmorphamin that respectively regulate TGF $\beta$ and SHh pathways and are associated with the proliferation of HSCs [13, 14].

- PD0325901 (PD) and Chir9901 (Chir) that regulate Wnt/ $\beta$-catenin and ERK pathways and play important role in HSCs differentiation [15-18].

- Bisperoxovanadium (Bpv) and Pifithrin- $\mu(\mathrm{P} \mu)$ that are associated with the pathways related to HSC survival like Akt and P53 [19, 20].

- Nicotinamide that facilitates the transcriptional epigenetic changes of chromatin [21].

The main question was whether a cocktail of these small molecules along with SCF, TPO, and Flt3L, the common cytokines which are basically used in the culture media of hematopoietic stem cells [22], could improve the self-renewal and transplantation potential of ex vivo expanded cells. To find the best combination, the eliminative approach was used, in which the components of a system are removed one by one; then, the interaction between the other components is investigated and the system is re-constructed. Here, we report that a cocktail consisting of SB, Chir, and Bpv is effective in promoting the cord blood hematopoietic stem cell proliferation while their stemness and in vivo engraftment potential maintained.

\section{Methods}

\section{Ethical approval}

All the experiments in this study were reviewed and approved by the Research Ethics Committee of the Royan Institute and were conducted in accordance with the ethical principles and the national norms and standards for conducting the Medical Research in Iran (IR.ACECR.ROYAN.REC.1398.189).

\section{Isolation of $\mathrm{CD} 4^{+}$cells}

A schematic illustration of the procedure was shown in Supplementary Fig. 1. Umbilical cord blood (UCB) samples were obtained from the Royan Cord Blood Bank. The collection of UCB was performed with the informed consent of the mother. Mononuclear cells were isolated using hydroxyethyl starch (Grifols, Spain) followed by LymphoprepTM (Stem cell Technology Inc.) densitygradient centrifugation. To isolate $\mathrm{CD} 34^{+}$cell, immunomagnetic selection kit (Miltenyi Biotec, Germany) was used. Highly purified (>90\%) CD34 ${ }^{+}$cells were confirmed by flow cytometry (Partec PAS system, USA) and then prepared to expand in different culture condition.

\section{MTS assay}

To determine the maximum tolerated dose of small molecules, the MTS assay was performed. At first, the initial concentration of small molecules was selected based on the previous studies (Supplementary Table 1). Two-point lower and two-higher concentrations were selected for cytotoxic assay. Briefly, cells were seeded into 96-well plates at a density of $1.0 \times 10^{4}$ cells/well in different concentrations of small molecules for $48 \mathrm{~h}$. Control cells received an equal amount of $10 \%$ FBSIMDM medium without any small molecule. Then, $100 \mu \mathrm{L}$ of MTS (promega) was subsequently added to each well and then incubated in the dark at $37^{\circ} \mathrm{C}$ for at least $1 \mathrm{~h}$. The absorbance was measured at $490 \mathrm{~nm}$. All groups were normalized to the same control group, and significant data was calculated using one-way ANOVA. All data were collected from five independent experiments.

\section{Ex vivo expansion}

Umbilical cord blood CD $34^{+}$cells were cultured for 10 days in the serum-free StemSpan ${ }^{\text {тм }}$ medium (Stem Cell Technology Inc.) supplemented with $100 \mathrm{ng} / \mathrm{mL}$ stem cell factor (SCF), $100 \mathrm{ng} / \mathrm{mL}$ Fms-related tyrosine kinase 3 ligand (Flt3-L), and $50 \mathrm{ng} / \mathrm{mL}$ thrombopoietin (TPO), all from R\&D. Seven small molecules: SB $(10 \mu \mathrm{M}), \mathrm{Bpv}$ $(5 \mu \mathrm{M})$, NAM $(2.5 \mu \mathrm{M})$, Pur $(4 \mu \mathrm{M}) \mathrm{PD}(0.25 \mu \mathrm{M})$, Chir $(0.37 \mu \mathrm{M})$, and $\mathrm{P} \mu(2.5 \mu \mathrm{M})$ were added to the media. $\mathrm{CD} 4^{+}$cells treated just with cytokines served as a positive control. The cells were maintained at $37^{\circ} \mathrm{C}$ in a humidified atmosphere containing $5 \%$ of $\mathrm{CO}_{2}$ and passaged every 3 days. Total nuclear cells were enumerated 
by trypan blue, and cellular expansion fold was calculated based on the initial inputs.

\section{Immunophenotyping of expanded cells}

Cells were collected and stained with an anti-human CD34 monoclonal antibody conjugated to phycoerythrin (PE; BD Pharmingen ${ }^{\mathrm{Tm}}$ ) and an anti-human CD38 monoclonal antibody conjugated to allophycocyanin (PerCP$\mathrm{Cy}^{\mathrm{mw}}$ 5.5, BD Pharmingen $\left.{ }^{\mathrm{Tw}}\right)$, together or separately. The appropriate isotype control antibodies were used for setting the Partec PAS system. At least $10^{4}$ events were acquired and data was analyzed using FlowMax software.

\section{Colony-forming assay}

Colony-forming units (CFUs) were generated by seeding 300 expanded cells into $1.1 \mathrm{ml}$ methylcellulose media (H4434, Stem Cell Technologies, Canada) diluted with $\mathrm{IMDM}+2 \% \mathrm{FBS}$ at a ratio of $1 / 10$. The colonies including burst-forming unit-erythroid (BFU-E), CFU granulocytemacrophage (CFU-GM), and CFU granulocyte-erythrocytemacrophage-megakaryocyte (CFUs-GEMM) were scored based on their morphology on day 14-16 at $\times 4$ magnification under an inverted microscope. All experiments were done as duplicates; all colonies were counted by an expertise in hematological colony counts and a mean of at least three independent experiments was reported.

\section{RNA extraction and qPCR}

Total RNA was isolated using QIAzol lysis reagent. The integrity and quality of RNA samples were checked using a Nano Drop (ND-1000) spectrophotometer. One microgram of the total RNA was subjected to reverse transcription using oligo-dT and PrimeScriptTM 1ststrand cDNA kit (Takara, Japan). Transcript levels were determined using the SYBR Green master mix and Corbett Rotor-Gene 6000. The GAPDH-normalized transcript data are shown as relative expression levels in the small molecules cocktail compared to the corresponding level in a positive control group. The primer sequences for qRTPCR are listed in Supplementary Table 2.

\section{Animals and xeno-transplantation study}

Xeno-transplantation was done as reported previously by our group [23]. Briefly, on embryonic days E11.5E13.5, each NMRI embryo injected intraperitoneally with $2-3 \times 10^{4}$ fresh $\mathrm{CD} 34^{+}$cells or their entire progeny following 10 days of expansion. To repopulate $\mathrm{CD}^{+} 4^{+}$cells, newborn mice were treated with human hematopoietic growth factors (interleukin 3 (IL-3) $4 \mathrm{ng} / \mathrm{g}, \mathrm{SCF}(4 \mathrm{ng} / \mathrm{g}$ ), and granulocyte colony-stimulating factor (G-CSF) 50 $\mathrm{ng} / \mathrm{g}$ ), beginning at 3 weeks of age. Then, the percentage of human CD45 cells (as a marker of human chimerism) in the peripheral blood of recipients was assessed monthly up to 4 months post birth. After staining the peripheral blood with anti-human CD45, at least $10^{5}$ cells were analyzed on a Partec system. Engraftment is defined as the detection of $0.2 \%$ or more human CD 45 cells.

\section{Statistical analysis}

All the data were presented as mean $\pm \mathrm{SD}$ of at least three different biological replicates. One way ANOVA was used to analyze the MTS assay data and the twotailed Student's $t$ test was used for statistical comparisons between the groups. $P<0.05$ was considered a statistically significant difference.

\section{Results}

Optimization of small molecule doses for HSC expansion

The proper concentration of selected small molecules which was not cytotoxic for CD34 $4^{+}$cells was determined using MTS assay (Fig. 1). In consistent with the other studies, CD34 ${ }^{+}$cells cultivated in $\mathrm{SB}(10 \mu \mathrm{M})$, Bpv $(5 \mu \mathrm{M})$, NAM $(2.5 \mu \mathrm{M})$, and Pur $(4 \mu \mathrm{M})$ were viable. However, predetermined concentrations of PD $(1 \mu \mathrm{M})$, Chir $(3 \mu \mathrm{M})$, and $\mathrm{P} \mu(10 \mu \mathrm{M})$ were toxic for UCB-HSCs. Therefore, lower concentrations of PD $(0.25 \mu \mathrm{M})$, Chir $(0.37 \mu \mathrm{M})$, and $\mathrm{P} \mu(2.5 \mu \mathrm{M})$ were added to the culture medium.

\section{$\mathrm{SB}$, Chir, and Bpv are sufficient for ex vivo expansion of UCB-CD $34^{+}$cells}

We next did some serial experiments (Supplementary Fig. 1). In the first round of experiments, isolated UCB$\mathrm{CD}_{4}{ }^{+}$cells were cultured in the presence of cytokines (SCF, TPO, and Flt3L) and selected small molecules. In the other groups, small molecules were deleted one by one from the pool of $7 \mathrm{SMs}$. Although, individual removal of SB, Chir, Bpv, Pur, NAM, and $\mathrm{P} \mu$ did not make significant differences in total nuclear cell (TNC) number compared to the 7SM group, removal of PD yielded an increased total number of mononuclear cells (Fig. 2a). The precise effect of PD on ex vivo expansion of CD34 ${ }^{+}$ cells has been discussed before [16]. An additional round of small molecules removal showed that the deletion of NAM and Pur from the cocktail increased the fold expansion of TNCs and CD34 $4^{+}$cells. Furthermore, the groups lacking NAM and Pur had a higher colonyforming potential, especially CFU-GM, compared to other groups containing small molecules (Fig. 2b). In the next round, by removing $\mathrm{P} \mu$, the number of $\mathrm{CD} 34^{+}$cells, CFU-GM, and CFU-GEMM colonies was increased significantly compared to the $\mathrm{PC}$ group (Fig. 2c). In the final round, removal of $\mathrm{SB}$, Chir, or Bpv reduced the expansion of $\mathrm{CD}_{3} 4^{+} \mathrm{CD} 38^{-}$cells and abolished the formation of CFU-GM and CFU-GEMM colonies, showing that these are essential for $\mathrm{CD}_{3} 4^{+}$cell expansion (Fig. 2d). Although, there was no significant difference 

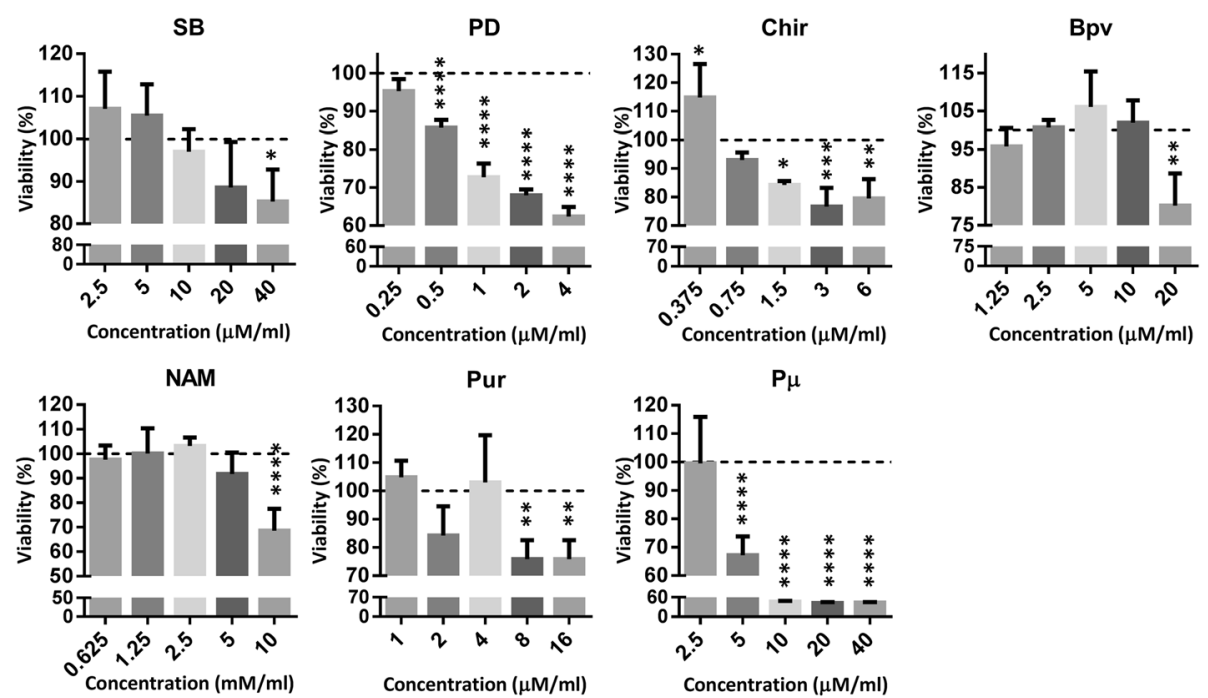

Fig. 1 Dose finding and optimization for small molecules (SB, Bpv, NAM, Pur, PD, Chir, P $\mu$ ). In each graph, the middle column corresponds to the reference concentration of the small molecules based on the literatures. Cell viability was measured by MTS assay post $48 \mathrm{~h}$ incubation with small molecules. The negative control in each group was used for the normalization of data. Bars indicated as mean \pm SD at least five independent replicates. ${ }^{*} P \leq 0.05,{ }^{* *} P \leq 0.01,{ }^{* * *} P \leq 0.001,{ }^{* * *} P \leq 0.0001$

between the 3SMCs and the positive control in terms of $\mathrm{TNC}$ expansion, removal of Bpv slightly increased the TNC fold expansion compared to the 3SM group (118 to 140). Moreover, the exclusion of each of the remaining three SMs (SB, Chir, or Bpv) had a dramatic negative impact on the expansion $\mathrm{CD} 34^{+} \mathrm{CD} 38^{-}$cells. Expansion with these three SMs (SB, Chir, and Bpv) produced a 2.7fold increase in the number of $\mathrm{CD} 34^{+} \mathrm{CD} 38^{-}$cells relative to a positive control (17 vs. 47). Finally, a CFU assay was performed to determine if the optimal SM cocktail actually promotes the expansion of hUCB-HPCs. As shown in Fig. 2d, the number of total CFUs increased more than 3fold when $\mathrm{CD}_{3} 4^{+}$cells was expanded in the presence of $\mathrm{SB}$, Chir, and $\mathrm{Bpv}$ for 10 days compared to the positive control. The expanded cells generated significantly more BFU and CFU-GM than the positive control $(p<0.01)$. However, the number of GEMMs in the SM group was slightly greater than that of the $\mathrm{PC}$, but the difference was not statistically significant $(p>0.05)$.

\section{The ability of 3SM cocktail to enhance the short-term} engraftment potential of ex vivo expanded $\mathrm{CD}_{3} 4^{+}$cells in the in utero transplanted NMRI mice

In order to evaluate the in vivo functional capability of the expanded $\mathrm{CD} 34^{+}$cells, we used in utero transplantation model [23]. We transplanted $30-50 \times 10^{3}$ freshly isolated hUCB-CD34 ${ }^{+}$cells or the cells harvested from the cultures with the same number of input hUCBCD34 ${ }^{+}$cells in the presence or absence of SM cocktail into NMRI mouse embryos, E11.5-E13.5. Two weeks after birth, born mice were treated with human hematopoietic growth factors SCF (4 ng/g), IL-3 (4 ng/g), and G-CSF (50 ng/g) for 1 week. As shown in Fig. 3, by treatment with the human hematopoietic factor, the $\mathrm{hCD} 45^{+}$chimerism was distinctly increased compared with initial values, 4 and 8 weeks post transplantation. Sixteen weeks after transplantation, the average human cell engraftment in the peripheral blood of the mice transplanted with freshly isolated hUCB CD34 ${ }^{+}$cells was about $1 \%$, while the percentage of $\mathrm{CD} 45^{+}$cells in $3 \mathrm{SMs}$ and positive control transplanted mice was 9 times and 3.4 times (3.6 \pm 1 and $3.2 \pm 0.3$ ) respectively, compared to the unexpanded cell recipients (Fig. 3). In the other words, the ex vivo expansion of hUCB CD34 ${ }^{+}$cells with SM cocktail resulted in 1.5 fold increase in human cell engraftment compared to the positive control.

\section{Ability of the optimal SM cocktail to modulate the cell signaling pathways}

Subsequently, RT-qPCR was performed in order to determine the expression of typical genes involved in HSC stemness. The result shows that the relative expression of the two major genes involved in the proliferation and self-renewal of HSCs, including HOXB4 and GATA2 as well as the HSC-specific marker, CD34, have significantly increased in the presence of 3SM cocktail after normalization to the level of the PC group. Furthermore, the expression of the CXCR4 gene involved in the migration and transplantation of HSCs has increased dramatically in the presence of 3SM cocktail. The expression of other genes associated with self-renewal, such as ABCG2, Notch, and Bmil, does not show a significant difference between the groups (Fig. 4). 

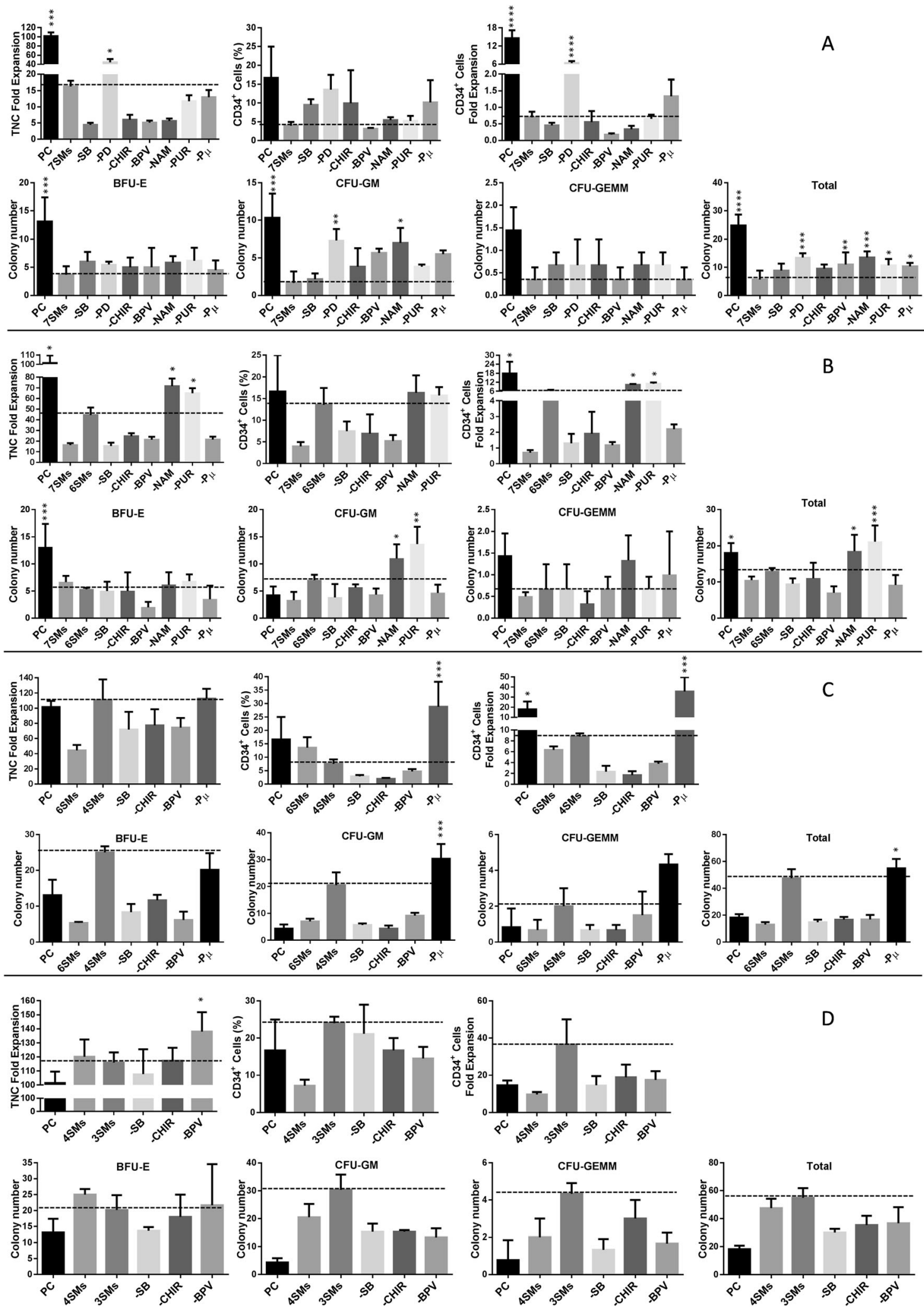

Fig. 2 (See legend on next page.) 
(See figure on previous page.)

Fig. 2 Characterization of expanded UCB-CD34 ${ }^{+}$cells in the presence/absence of different combinations of small molecules. TNC fold expansion, $\mathrm{CD}_{4}{ }^{+}$cells percentage, fold expansion of $\mathrm{CD} 34^{+}$cells, and colony-forming potential of UCB-CD34 ${ }^{+}$cells was evaluated in each experiment. a 7 SM cocktail (SB, PD, Chir, Bpv, NAM, Pur, P $\mu$ ) and its derivative groups b 6 SMs cocktail (SB, Chir, Bpv, NAM, Pur, P $\mu$ ) and its derivative groups c 4 SMs cocktail (SB, Chir, Bpv, Pu) and its derivative groups d 3 SMs cocktail (SB, Chir, Bpv). CD34 ${ }^{+}$cells cultivated in presence of SCF, FLT3L, and TPO were used as a positive control. Fold expansion was determined by dividing the total number of viable cells expressing the phenotype at the end of the culture by the input number of viable cells expressing the same phenotype $(n=3)$. A statistically significant difference compared with a positive control group, ${ }^{*} P \leq 0.05,{ }^{* *} P \leq 0.01,{ }^{* * *} P \leq 0.001$

\section{Discussion}

In recent years, small molecules have been widely used in the field of stem cell research. So far, there have been numerous indications for the successful use of small molecules to inhibit apoptotic and differentiation processes during hematopoietic stem cell reproduction [8]. It seems that a combination of two or more small molecules may produce a better result. For example, the effect of chir and insulin [10], chir, and rapamycin [24] along with SCF, TPO, and Flt3L has been reported to enhance the proliferation of mouse hematopoietic stem cells. The proliferation of human hematopoietic stem cells has also been studied in the presence of various combinations of 5Aza, TSA, VPA, and NAM [25-27]. Notably, based on the cell status, synergistic/antagonistic interactions may have been created between the small molecules. As a result, the simultaneous use of small molecule compounds can produce unpredictable results compared to their individual use. To our knowledge, this is the first study in which the expansion of $\mathrm{CD} 34^{+}$cells is targeted through the simultaneous modulation of proliferation, differentiation, and apoptosis signaling pathway.

In this study, a cocktail of seven small molecules was selected to target the TGF $\beta$, ERK, Wnt, Akt, Hedgehog, and P53 signaling pathways as well as the cell epigenome. Then, their best combination to induce efficient HSC expansion was screened through the eliminative approach. To the successful expansion of UCB-CD34 ${ }^{+}$ cells, SCF, TPO, and Flt3L which greatly affect the HSC signaling pathways were also added to the culture medium. Our experiments conducted us to this notion that the addition of SB, Chir, and Bpv to the HSC conventional HSC culture medium increases the efficiency of ex vivo expansion of $\mathrm{CD} 34^{+}$cells with 50 -fold enhancement in the number of $\mathrm{CD} 4^{+} 38^{-}$cells. The small molecule cocktail can also augment the colony formation ability of expanded cells (Fig. 2). All these changes were associated with the upregulation of HOXB4, GATA2, and CD34 gene. Moreover, here, higher engraftment potential and higher percentage of human CD45 cells in infused mice confirm the in vivo potential of the expanded cells in the presence of small-molecule cocktail.

According to our findings, the best result is obtained by simultaneous controlling of PTEN/Akt, Wnt/B-catenin, and TGF $\beta$ signaling pathways in such a way that Bpv leads to exiting the cells from the quiescence and proliferation through inhibiting PTEN and enhancing the Akt pathway. On the other hand, Chir indirectly inhibits the differentiation process through GSK3 inhibition and $\beta$-Catenin activation. All of these events occur while TGF $\beta$, the most important apoptotic pathway, is inhibited by SB (Fig. 5).

PI3K-AKT pathway is one of the most important pathways affecting a wide range of stem cell cellular signaling molecules [28]. In particular, many apoptotic proteins
A.

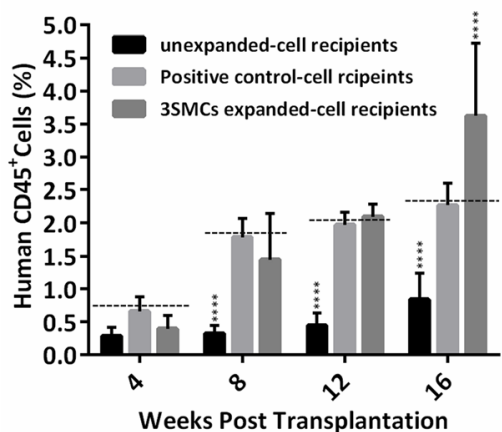

B.

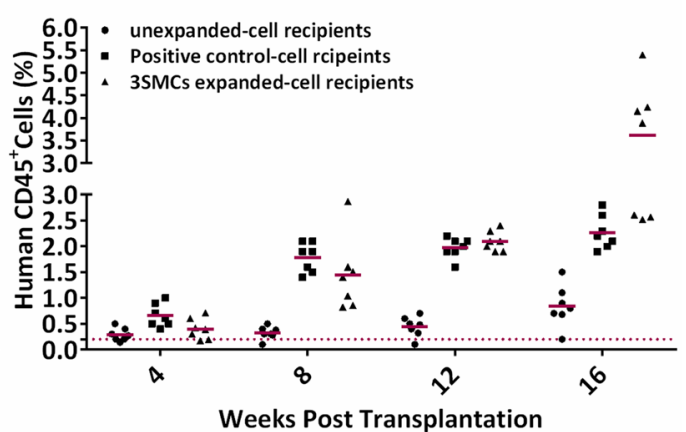

Fig. 3 The level of expanded hUCB-CD34+ cells engraftment in the peripheral blood of NMRI mice. a The percentage of human CD45 cells in the peripheral blood of newborn mice. Each bar indicated mean \pm SD for at least 6 independent samples. ${ }^{* * *} P \leq 0.0001$. $\mathbf{b}$ Each shape indicates the percentage of human CD45 expression in the peripheral blood of one newborn mouse. Mice with $\geq 0 \cdot 2 \%$ human cells were considered chimeric 


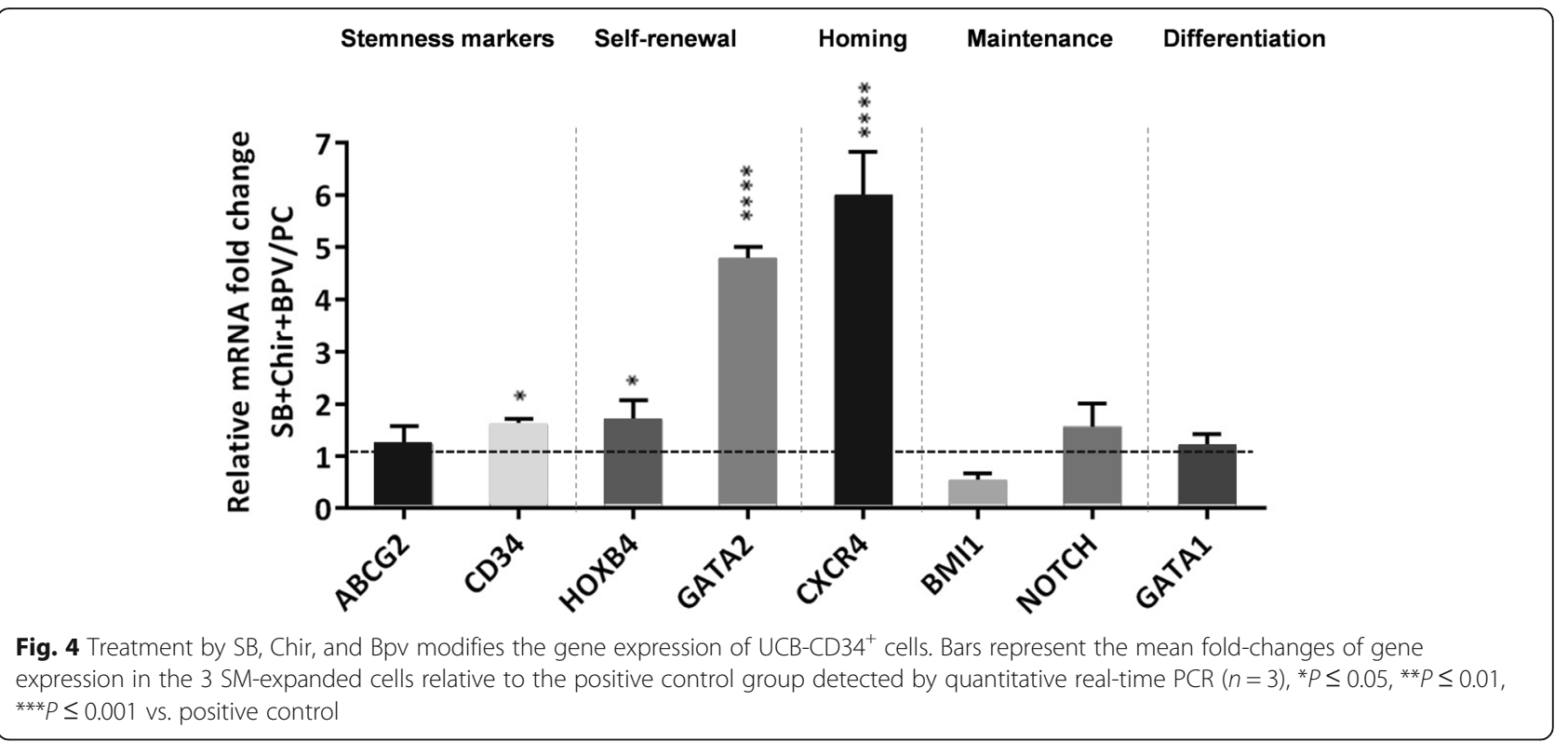

such as Bim and Bcl-2 can be inactivated by the pathway. AKT, also, inhibits certain cell cycle inhibitors such as P21 and P27 and activates Cyclin D, which in turn leads to exit from G0 and entry into the cell cycle [29]. Furthermore, Akt facilitates the migration of HSCs and their binding to the bone marrow stromal cells through induction of integrin expression [30, 31]. PTEN is a tumor suppressor protein that inhibits the PI3K-AKT pathway. Actually, inhibition of PTEN leads to increased survival, proliferation, self-renewal, and incomplete differentiation potential of embryonic stem cells [32] and also in vitro proliferation of HSCs [10].

Wnt pathway not only plays a critical role in the development of embryonic stem cells [33], but also in the proliferation and differentiation of adult stem cells including HSCs [34, 35]. The major effects of Wnt are applied through $\beta$-catenin which can increase the self-renewal and proliferation of HSCs, even independently of the Wnt pathway [36, 37]. According to previous studies, the accumulation of the $\beta$-catenin, following GSK3 inactivation,

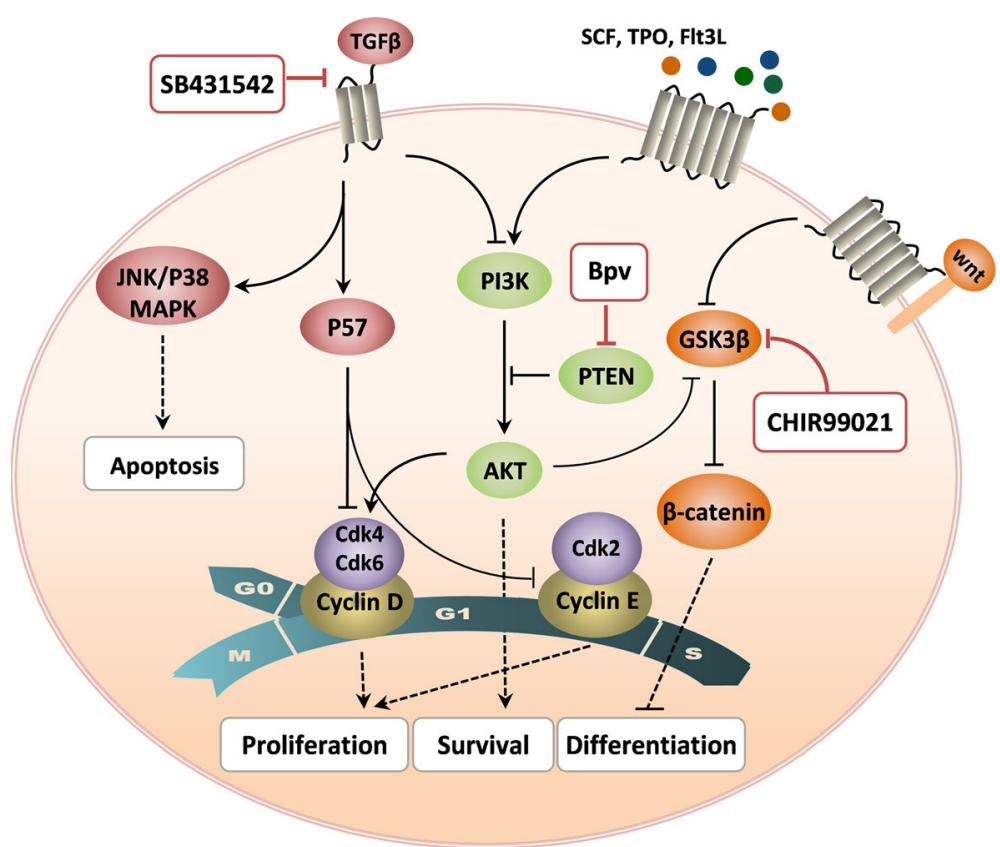

Fig. 5 The molecular mechanisms which through them SB, Chir, and Bpv modulate proliferation, differentiation, and survival of hematopoietic stem cells 
facilitates the maintenance of the pluripotency state of embryonic and adult stem cells [38, 39].

TGF $\beta$ is one of the major negative regulators of HSC proliferation [40]. The pathway, specifically, inhibits cell cycle progression through the induction of P57 expression, which in turn leads to CyclinD-Cdk4/6 and CyclinE-Cdk2 inactivation. P38MAPK is also a downstream molecule of the TGF $\beta$ pathway which its inhibition results in decreased in vitro apoptosis and aging of HSCs [40]. JNK is another downstream target of TGF $\beta$ which activates some apoptotic factors such as Bcl2 and Bad. Therefore, inhibition of the TGF $\beta$ pathway not only leads to P57, P38MAPK, and JNK inhibition which is associated with cell cycle promotion, but also inhibits the apoptotic pathways [41-43].

Altogether, a cocktail of SB431542, Chir99021, and Bpv, which respectively inhibits the TGF $\beta$ differentiation pathway and activates the Wnt and Akt pathways, can be used to improve the conventional protocol of HSC expansion.

\section{Supplementary information}

Supplementary information accompanies this paper at https://doi.org/10. 1186/s13287-020-01945-8.

Additional file 1: Figure S1. Schematic illustration of procedure to find the best combination of small molecules to expand UCB-HSCs. Table S1. Initial concentration of small molecules based on previous studies and their proper concentration based on MTS assay. Table S2. List of primer sequences used in the present study.

\section{Abbreviations}

UCB: Umbilical cord blood; HSCs: Hematopoietic stem cells; SMs: Small molecules; SB: SB431542; Pur: Purmorphamin; PD: PD0325901; Chit: Chir9901; Bpv: Bisperoxovanadium; P : Pifithrin- $\mu$; NAM: Nicotinamide; CFU: Colonyforming units; BFU-E: Burst-forming unit-erythroid; CFU-GM: CFU granulocytemacrophage; CFU-GEMM: CFU granulocyte-erythrocyte-macrophagemegakaryocyte

\section{Acknowledgements}

The authors would like to thank Zahra Pour-Safavi for her technical support in flowcytometery experiment and Azam Dalman for preparing the handmade glass pipettes. The authors declare no conflict of interest in this study.

\section{Authors' contributions}

M.Z. and E.A. performed all in vitro experiments, analyzed the data, and wrote the manuscript. M.H.A. performed in vivo experiment and analyzed the in vivo data. M.E. contributed to the concept and design, financial support, and final approval of the manuscript. The authors read and approved the final manuscript.

\section{Funding}

This study has been funded by the Royan Institute (code: 91000597) and granted partly by the Royan Stem Cell Technology Company, Iran.

\section{Availability of data and materials}

All data generated or analyzed during this study are included in this published article and in supplementary figures.

\section{Ethics approval and consent to participate}

All the experiments in this study were reviewed and approved by the Research Ethics Committee of the Royan Institute and were conducted in accordance with the ethical principles and the national norms and standards for conducting the Medical Research in Iran (IR.ACECR.ROYAN.REC.1398.189).

Consent for publication

Not applicable.

\section{Competing interests}

The authors declare that they have no competing interests.

\section{Author details}

${ }^{1}$ Department of Stem Cells and Developmental Biology, Cell Science Research Center, Royan Institute for Stem Cell Biology and Technology, ACEC R, P.O. Box, Tehran 19395-4644, Iran. ${ }^{2}$ Royan Stem Cell Technology Company, Cord Blood Bank, Tehran, Iran. ${ }^{3}$ Animal Core Facility, Reproductive Biomedicine Research Center, Royan Institute for Animal Biotechnology, ACECR, Tehran, Iran.

Received: 27 June 2020 Accepted: 20 September 2020

Published online: 09 November 2020

\section{References}

1. Roura S, Pujal JM, Galvez-Monton C, Bayes-Genis A. The role and potential of umbilical cord blood in an era of new therapies: a review. Stem Cell Res Ther. 2015:6:123.

2. $\quad$ lic D, Miere C, Lazic E. Umbilical cord blood stem cells: clinical trials in nonhematological disorders. Br Med Bull. 2012:102:43-57.

3. Cany J, Dolstra H, Shah N. Umbilical cord blood-derived cellular products for cancer immunotherapy. Cytotherapy. 2015;17(6):739-48.

4. Balassa K, Rocha V. Anticancer cellular immunotherapies derived from umbilical cord blood. Expert Opin Biol Ther. 2018;18(2):121-34.

5. Delaney C, Ratajczak MZ, Laughlin MJ. Strategies to enhance umbilical cord blood stem cell engraftment in adult patients. Expert Rev Hematol. 2010; 3(3):273-83

6. Derakhshani M, Abbaszadeh H, Movassaghpour AA, Mehdizadeh A, Ebrahimi-Warkiani M, Yousefi M. Strategies for elevating hematopoietic stem cells expansion and engraftment capacity. Life Sci. 2019;232:116598.

7. Oh IH, Lau A, Eaves CJ. During ontogeny primitive (CD34(+)CD38(-)) hematopoietic cells show altered expression of a subset of genes associated with early cytokine and differentiation responses of their adult counterparts. Blood. 2000;96(13):4160-8.

8. Zarrabi M, Afzal E, Ebrahimi M. Manipulation of hematopoietic stem cell fate by small molecule compounds. Stem Cells Dev. 2018:27(17):1175-90.

9. Gao $Y$, Yang $P$, Shen $H$, Yu H, Song $X$, Zhang L, et al. Small-molecule inhibitors targeting INK4 protein p18(INK4C) enhance ex vivo expansion of haematopoietic stem cells. Nat Commun. 2015;6:6328.

10. Perry JM, He XC, Sugimura R, Grindley JC, Haug JS, Ding S, et al. Cooperation between both Wnt/\{beta\}-catenin and PTEN/PI3K/Akt signaling promotes primitive hematopoietic stem cell self-renewal and expansion. Genes Dev. 2011;25(18):1928-42.

11. Sangeetha VM, Kale VP, Limaye LS. Expansion of cord blood CD34 cells in presence of zVADfmk and zLLYfmk improved their in vitro functionality and in vivo engraftment in NOD/SCID mouse. PLoS One. 2010;5(8):e12221.

12. Zou J, Zou P, Wang J, Li L, Wang Y, Zhou D, et al. Inhibition of p38 MAPK activity promotes ex vivo expansion of human cord blood hematopoietic stem cells. Ann Hematol. 2012:91(6):813-23.

13. Yamazaki S, Iwama A, Takayanagi S, Eto K, Ema H, Nakauchi H. TGF-beta as a candidate bone marrow niche signal to induce hematopoietic stem cell hibernation. Blood. 2009;113(6):1250-6.

14. Guo J, Wang S-Y, Zhu X-F, Li S-T, Lin F-L, Li X-M, et al. Effect of Shh and BMMSC synergism on the proliferation of hematopoietic stem cells. Zhongguo Shi Yan Xue Ye Xue Za Zhi. 2018:26(5):1523-30.

15. Kabiri Z, Numata A, Kawasaki A, Edison TDG, Virshup DM. Wnts are dispensable for differentiation and self-renewal of adult murine hematopoietic stem cells. Blood. 2015;126(9):1086-94.

16. Zarrabi M, Afzal E, Asghari MH, Mohammad M, Es HA, Ebrahimi M. Inhibition of MEK/ERK signalling pathway promotes erythroid differentiation and reduces HSCs engraftment in ex vivo expanded haematopoietic stem cells. J Cell Mol Med. 2018:22(3):1464-74.

17. Ruiz-Herguido C, Guiu J, D'Altri T, Inglés-Esteve J, Dzierzak E, Espinosa L, et al. Hematopoietic stem cell development requires transient Wnt/Bcatenin activity. J Exp Med. 2012;209(8):1457-68. 
18. Miranda MB, McGuire TF, Johnson DE. Importance of MEK-1/-2 signaling in monocytic and granulocytic differentiation of myeloid cell lines. Leukemia. 2002;16(4):683-92

19. Ghosh J, Kapur R. Regulation of hematopoietic stem cell self-renewal and leukemia maintenance by the PI3K-mTORC1 pathway. Curr Stem Cell Rep. 2016;2(4):368-78.

20. Liu Y, Elf SE, Miyata Y, Sashida G, Liu Y, Huang G, et al. p53 regulates hematopoietic stem cell quiescence. Cell Stem Cell. 2009:4(1):37-48.

21. Denu JM. Vitamin B3 and sirtuin function. Trends Biochem Sci. 2005;30(9): 479-83.

22. Suzuki T, Yokoyama Y, Kumano K, Takanashi M, Kozuma S, Takato T, et al. Highly efficient ex vivo expansion of human hematopoietic stem cells using Delta1-Fc chimeric protein. Stem cells (Dayton, Ohio). 2006;24(11):2456-65.

23. Zarrabi M, Afzal E, Asghari MH, Ebrahimi M. Assessment of short-term engraftment potential of ex vivo expanded hematopoietic stem cells using normal fetal mouse in utero transplantation model. Cell J. 2019; 21(3):259-67.

24. Huang J, Nguyen-McCarty M, Hexner EO, Danet-Desnoyers G, Klein PS Maintenance of hematopoietic stem cells through regulation of Wnt and mTOR pathways. Nat Med. 2012;18(12):1778-85.

25. Mahmud N, Petro B, Baluchamy S, Li X, Taioli S, Lavelle D, et al. Differentia effects of epigenetic modifiers on the expansion and maintenance of human cord blood stem/progenitor cells. Biol Blood Marrow Transplant. 2014;20(4):480-9.

26. Araki H, Mahmud N, Milhem M, Nunez R, Xu M, Beam CA, et al. Expansion of human umbilical cord blood SCID-repopulating cells using chromatinmodifying agents. Exp Hematol. 2006;34(2):140-9.

27. Araki H, Yoshinaga K, Boccuni P, Zhao Y, Hoffman R, Mahmud N. Chromatinmodifying agents permit human hematopoietic stem cells to undergo multiple cell divisions while retaining their repopulating potential. Blood. 2007;109(8):3570-8.

28. Yu JS, Cui W. Proliferation, survival and metabolism: the role of PI3K/AKT/ mTOR signalling in pluripotency and cell fate determination. Development (Cambridge, England). 2016;143(17):3050-60.

29. Chang F, Lee JT, Navolanic PM, Steelman LS, Shelton JG, Blalock WL, et al. Involvement of PI3K/Akt pathway in cell cycle progression, apoptosis, and neoplastic transformation: a target for cancer chemotherapy. Leukemia. 2003;17(3):590-603.

30. Los M, Maddika S, Erb B, Schulze-Osthoff K. Switching Akt: from survival signaling to deadly response. BioEssays. 2009;31(5):492-5.

31. Buitenhuis $\mathrm{M}$. The role of $\mathrm{PI} 3 \mathrm{~K} /$ protein kinase $B$ (PKB/C-akt) in migration and homing of hematopoietic stem and progenitor cells. Curr Opin Hematol. 2011;18(4):226-30

32. Jung CJ, lyengar S, Blahnik KR, Jiang JX, Tahimic C, Torok NJ, et al. Human ESC self-renewal promoting microRNAs induce epithelial-mesenchymal transition in hepatocytes by controlling the PTEN and TGFbeta tumor suppressor signaling pathways. Mol Cancer Res. 2012;10(7):979-91.

33. Merrill BJ. Wnt pathway regulation of embryonic stem cell self-renewal. Cold Spring Harb Perspect Biol. 2012;4(9):a007971.

34. Richter J, Traver D, Willert K. The role of Wnt signaling in hematopoietic stem cell development. Crit Rev Biochem Mol Biol. 2017;52(4):414-24.

35. Cain CJ, Manilay JO. Hematopoietic stem cell fate decisions are regulated by Wnt antagonists: comparisons and current controversies. Exp Hematol. 2013;41(1):3-16

36. Baba Y, Yokota T, Spits H, Garrett KP, Hayashi S, Kincade PW. Constitutively active beta-catenin promotes expansion of multipotent hematopoietic progenitors in culture. J Immunol (Baltimore, Md : 1950). 2006;177(4):2294-303.

37. Nemeth MJ, Mak KK, Yang Y, Bodine DM. beta-Catenin expression in the bone marrow microenvironment is required for long-term maintenance of primitive hematopoietic cells. Stem cells (Dayton, Ohio). 2009;27(5):1109-19.

38. Yu SJ, Kim HJ, Lee ES, Park CG, Cho SJ, Jeon SH. Beta-catenin accumulation is associated with increased expression of Nanog protein and predicts maintenance of MSC self-renewal. Cell Transplant. 2017;26(2):365-77.

39. Sanchez-Ripoll Y, Bone HK, Owen T, Guedes AM, Abranches E, Kumpfmueller B, et al. Glycogen synthase kinase-3 inhibition enhances translation of pluripotency-associated transcription factors to contribute to maintenance of mouse embryonic stem cell self-renewal. PLoS One. 2013; 8(4):e60148.

40. Blank U, Karlsson S. TGF-beta signaling in the control of hematopoietic stem cells. Blood. 2015;125(23):3542-50.
41. Wang C, Tang X, Sun X, Miao Z, Lv Y, Yang Y, et al. TGFbeta inhibition enhances the generation of hematopoietic progenitors from human ES cellderived hemogenic endothelial cells using a stepwise strategy. Cell Res. 2012;22(1):194-207.

42. Zhang Y, Alexander PB, Wang XF. TGF-beta family signaling in the control of cell proliferation and survival. Cold Spring Harb Perspect Biol. 2017;9(4): a022145.

43. Hinge A, Filippi MD. Deconstructing the complexity of TGFbeta signaling in hematopoietic stem cells: quiescence and beyond. Curr Stem Cell Rep. 2016;2(4):388-97.

\section{Publisher's Note}

Springer Nature remains neutral with regard to jurisdictional claims in published maps and institutional affiliations.
Ready to submit your research? Choose BMC and benefit from:

- fast, convenient online submission

- thorough peer review by experienced researchers in your field

- rapid publication on acceptance

- support for research data, including large and complex data types

- gold Open Access which fosters wider collaboration and increased citations

- maximum visibility for your research: over $100 \mathrm{M}$ website views per year

At BMC, research is always in progress.

Learn more biomedcentral.com/submissions 